\title{
Observations on the efficiency of using different cashmere combs
}

Article in Small Ruminant Research · September 2013

DOI: 10.1016/j.smallrumres.2013.06.013

CITATIONS

4

6 authors, including:

\section{Joaquin Mueller}

Instituto Nacional de Tecnología Agropecuaria 60 PUBLICATIONS 376 CITATIONS

SEE PROFILE

\section{Barbara Rischkowsky}

Consultative Group on International Agricult... 131 PUBLICATIONS 936 CITATIONS

SEE PROFILE

Sepehr Moradi

Deakin University

60 PUBLICATIONS 136 CITATIONS

SEE PROFILE

Some of the authors of this publication are also working on these related projects: 


\title{
Observations on the efficiency of using different cashmere combs
}

\author{
H.R. Ansari-Renani ${ }^{\text {a,* }}$, J.P. Mueller ${ }^{\text {b }}$, B. Rischkowsky ${ }^{\mathrm{c}}$, S.M. Seyed Momen ${ }^{\mathrm{d}}$, \\ M. Ehsani ${ }^{\mathrm{d}}$, S. Moradi ${ }^{\mathrm{e}}$ a \\ ${ }^{a}$ Animal Science Research Institute (ASRI), P.O. Box 31585-1483, Karaj, Islamic Republic of Iran \\ b National Institute for Agricultural Technology (INTA), Bariloche, Argentina \\ c International Center for Agricultural Research in the Dry Areas (ICARDA), Addis Ababa, Ethiopia \\ d Agriculture and Natural Resources Research Center, Kerman, Islamic Republic of Iran \\ e Animal Science Department, Agriculture College, University of Zanjan, Karaj, Islamic Republic of Iran
}

\section{A R T I C L E I N F O}

Article history:

Received 27 April 2012

Received in revised form 16 June 2013

Accepted 18 June 2013

Available online 22 July 2013

\section{Keywords:}

Goat

Down fiber

Down yield

Fiber diameter

\begin{abstract}
A B S T R A C T
The effect of using small or large cashmere combs on cashmere harvest, cashmere quality and combing time was studied on Raeini cashmere goats in nomadic goat breeding systems of the Iranian province of Kerman. Two groups of 20 goats of different ages were combed with either a large or a small comb, three times with intervals of 2 weeks in early spring when natural fiber shedding has started. Combed cashmere weight, duration of combing, fiber diameter, and down yield were measured. A sample of combed cashmere was analyzed using a Laserscan instrument. A general linear model including type of comb, stage of combing and age of goat was fitted to analyze the data. Small combs collect more cashmere (31.0 vs. $21.7 \mathrm{~g}, P<0.01)$ than large combs without affecting down yield or down fiber diameter $(P>0.05)$ but combing time is higher ( $3.75 \mathrm{vs.} 2.79 \mathrm{~min}, P<0.01)$. In the first two combing sessions much more cashmere was obtained than in the last $(28.1,32.0$ and $19.0 \mathrm{~g}$, respectively, $P<0.01$ ), but the weight of total combed cashmere was much less than typical shorn fleece weights. Combing can be justified only if a considerable price premium can be obtained from selling combed cashmere instead of selling shorn cashmere, or if the combed cashmere is used to add value on-farm. If this is the case, small combs with short rods are preferable since more cashmere can be collected without affecting its quality.
\end{abstract}

(c) 2013 Elsevier B.V. All rights reserved.

\section{Introduction}

Dehaired cashmere is one of the finest, softest and most expensive luxury natural fibers used mainly for clothing providing warmth and lightness. Iran together with Afghanistan is the third largest producer and exporter of cashmere, after China and Mongolia. Of the 25 million goats in Iran, 5 million produce cashmere. Main cashmere goat breeds in Iran are Raeini, Birjandi, Abadeh and Nadoushan which are kept in the provinces of Kerman, South Khorasan,

\footnotetext{
* Corresponding author. Tel.: +1198 34464228; fax: +98 2614413258.

E-mail address: ansarirenani@yahoo.com (H.R. Ansari-Renani).
}

Fars and Yazd, respectively. Nomads keep 40\% of the goat population in a habitat of about $59 \%$ of the total area of the country. Besides meat and milk for home consumption, cashmere provides a substantial part of nomads' cash income (Ansari-Renani et al., 2013).

In the main cashmere producing provinces of Kerman and Yazd, cashmere is harvested by shearing goats with double blade knives in spring. Survey data from Kerman province revealed that $52 \%$ and $30 \%$ of farmers sheared their goats in May and April while $11 \%$ and $7 \%$ do so in March and June, respectively (Ansari-Renani et al., 2013). In early spring (March) cashmere goats start a sequential, bilaterally symmetric pattern of shedding their fine undercoat fibers commencing on the neck, chest and shoulders 


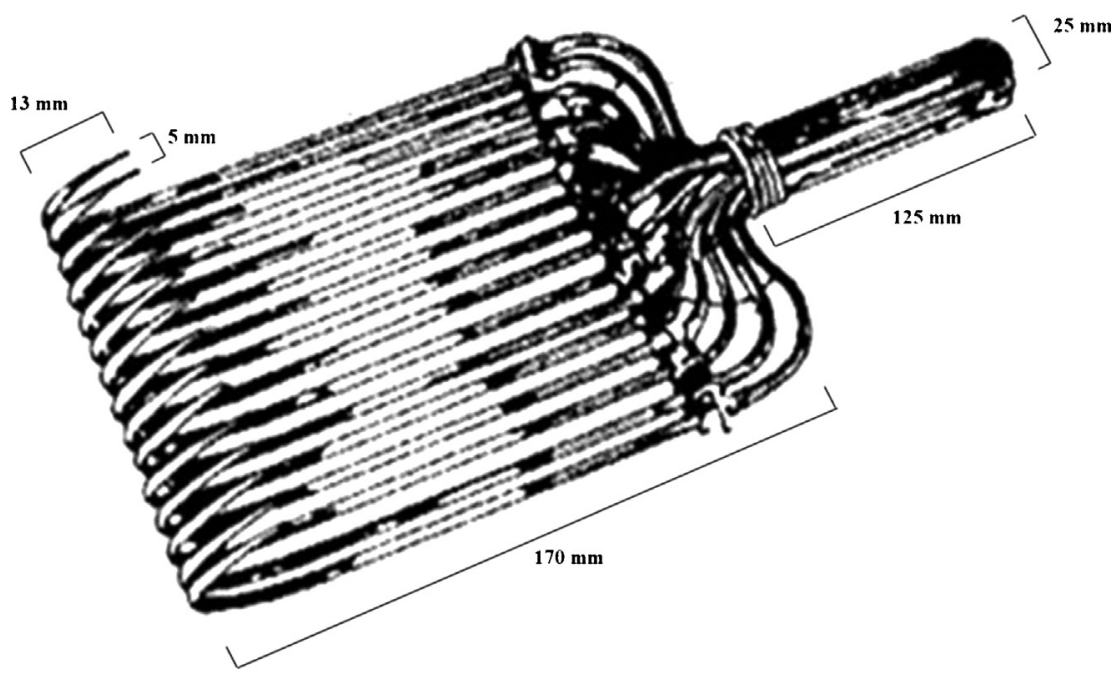

Adapted from Petrie (1995).

Fig. 1. Large cashmere comb with long curled metal rods and metal slide and handle.

spreading to the back and rump (Ansari-Renani, 2001). Shed fibers remain some time entangled in the rest of the fleece but eventually fall off the animal. In fact, fiber follicle studies on Raeini goats of Kerman showed that in March $24.4 \%$ of secondary follicles are inactive (AnsariRenani et al., 2011a). Since photoperiod in this month is quickly increasing, follicles reactivate and induce shedding. Thus, shearing is usually well after the onset of the fiber shedding period preventing the collection of all cashmere produced.

Raw cashmere buyers prefer shorn fleeces which are white, soft (related to fineness), clean (free from dirt and vegetable matter), high yielding (high percentage of undercoat or down fibers) and with long down fibers (Ansari-Renani et al., 2011b). Combed cashmere carries fewer guard hairs produced by primary follicles and has therefore a higher percentage of down fibers than shorn cashmere. It can also be speculated that combed cashmere has longer down fibers since shearing will leave a fraction of the fiber on the skin of the animal. Thus, combed cashmere should fetch better prices and combing cashmere has been recommended instead of shearing (Petrie, 1995). However combing may be laborious and time consuming. Studies on the advantages and disadvantages of combing vs. shearing cashmere in Afghanistan concluded with the recommendation to promote combing (De Weijer, 2008), while alerting on the need of further information pertaining to the advantages and disadvantages of both harvesting techniques so that farmers can take an informed decision.

Promotion of combing in the main cashmere producing regions of Iran would also need careful analyses and information on advantages and disadvantages. For a start, combs are not used but different comb types are available to farmers. There are combs with long rods such as regularly used in China and combs with short rods more common in Afghanistan and Turkey (Gökmen and Boztepe, 2004). Information on the time needed to comb a Raeini goat as opposed to shearing is needed, as well as the worth of repeated combings of the same animal, and whether the use of different comb types and combing regimes is independent of the age of the animal. We investigated the effect of using different cashmere combs and combing regimes on combing time and cashmere traits in goats of different ages.

\section{Materials and methods}

\subsection{Study area and experimental goats}

An experiment to examine the efficiency of using different cashmere combs was undertaken on goats near the city of Baft $\left(29^{\circ} 17^{\prime} \mathrm{N} 56^{\circ} 36^{\prime} \mathrm{E}\right)$ located in the province of Kerman where altitude is about 2300 masl and annual precipitation varies from 180 to $320 \mathrm{~mm}$. The climate in spring and summer when nomads graze their goats in the region is hot and relatively dry, with temperatures reaching $35^{\circ} \mathrm{C}$. In autumn nomads migrate with their goats to the southern Persian Gulf provinces of Hormozgan and Bushehr. The winter grazing area of Hormozgan province is about 3300 masl with dry and warm weather and annual precipitation of $170 \mathrm{~mm}$.

Cashmere goats in the region are of the Raeini breed which has an average live weight of $35 \mathrm{~kg}$ for males and $30 \mathrm{~kg}$ for females (Emami Meibodi, 1992). In typical Raeini flocks, goats are shorn annually in April-May producing on average $507 \mathrm{~g}$ of raw cashmere with $56.5 \%$ down yield, $19.5 \mu \mathrm{m}$ down fiber diameter and a staple length of $54.2 \mathrm{~mm}$ (Ansari-Renani et al., 2012). For the experiment we selected randomly in one flock 10 white female goats of $1,2,3$ and 4 years of age. Age of goats was determined by inspection of the dental plaque. The 40 goats were divided into two groups of 20 with 5 goats of each age group. The experimental animals were identified and kept together with the rest of the flock on pasture without supplementary feeding.

\subsection{Combs and combing regime}

Each group of 20 goats was combed using either a large or a small comb (Mongolian type). The large comb is made of 15 metal rods, which are curved round and have a radius of $13 \mathrm{~mm}$ with the tips being rounded to form a sharpened end (Fig. 1). The comb fingers are spring steel $1.5 \mathrm{~mm}$ in diameter and approximately $170 \mathrm{~mm}$ in length. The handle is $125 \mathrm{~mm}$ in length and $25 \mathrm{~mm}$ in diameter. Adjustments are made by means of a metal slide which moves the teeth either closer together or further apart. This slide also assists in removing the hair from the comb. The width of comb at the narrowest and widest distance adjusted by metal slide is 90 and $140 \mathrm{~mm}$, respectively. The small comb used is made of 26 metal rods, with a length of $25 \mathrm{~mm}$ and $5 \mathrm{~mm}$ distance between the rods and a diameter of $1 \mathrm{~mm}$ (Fig. 2). The nonadjustable width of comb is $100 \mathrm{~mm}$ 


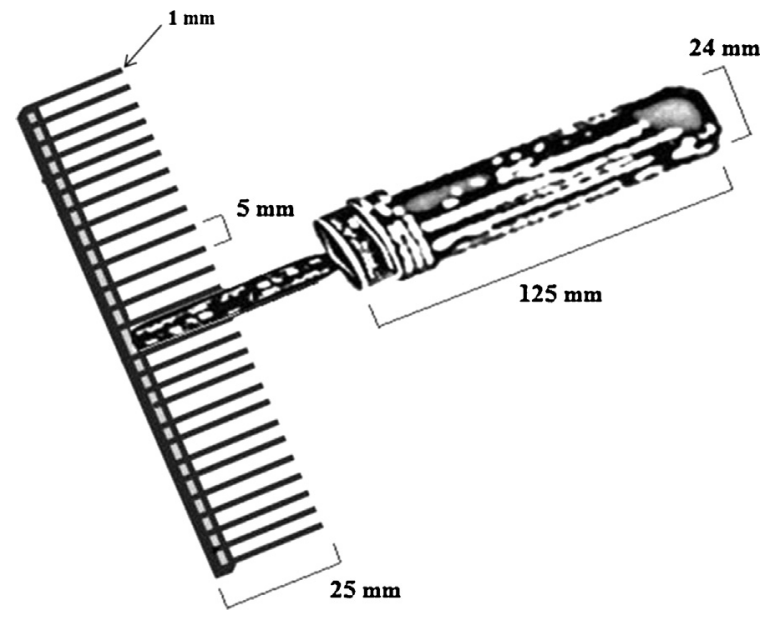

Fig. 2. Small cashmere comb with short straight metal rods and a wooden handle.

that is connected to a wooden handle of $120 \mathrm{~mm}$ long and $24 \mathrm{~mm}$ wide by a metal rod of $40 \mathrm{~mm}$ length.

Combing was carried out in three sessions at 2 weeks intervals starting end of March 2011 with the commencement of the shedding season. In order to facilitate combing, goats were tethered in a standing position for combing which was done in short, pulling strokes. Fiber growth was about 11 months and the environmental conditions during the fiber growth period were stated as normal. Goats had been shorn in the previous shearing season. At each combing session goats were combed until all loose down fibers were collected. If an insufficient quantity of fibers was obtained from the first couple of strokes it was assumed that the goat was not yet shedding and it was left until the next visit. The time spent in combing each goat (expressed in min) was registered and the combed cashmere obtained (CCW, expressed in $\mathrm{g}$ ) was weighed using a digital scale. A fiber sample representing the whole fleece as proposed by McGregor (1994) was taken and kept in separate bags for laboratory analyses.

\subsection{Fiber analyses}

The combed cashmere samples were analyzed at the Fiber Laboratory of the National Institute for Agricultural Technology in Bariloche, Argentina. The samples were minicored and degreased with hexane to produce $2 \mathrm{~mm}$ clean fiber snippets. Fiber diameter of about 4000 snippets per sample was measured using a Sirolan Laserscan instrument and IWTO 12-03 standard procedures (IWTO, 2003). Fibers up to $30 \mu \mathrm{m}$ were considered as down fibers and fibers above $30 \mu \mathrm{m}$ as guard hairs. The same arbitrary fiber separation threshold was also used by McGregor et al. (2011). Mean fiber diameter was calculated for the down fibers and for the hair fibers (DD and HD, respectively, expressed in $\mu \mathrm{m}$ ). Down yield (DY, expressed in \%) was estimated using the Wildman-Bray formula (Wildman, 1954) and considering down fiber density to be $1.31 \mathrm{~g} / \mathrm{cm}^{3}$ as indicated by IWTO 58-00 standard procedures (IWTO, 2000). Guard hair density was taken as $0.93 \mathrm{~g} / \mathrm{cm}^{3}$ following Herrmann and Wortmann (1997). Thus, down yield is the proportion of fibers up to $30 \mu \mathrm{m}$ of all fibers in the combed cashmere sample, adjusted for the differential weight of the two types of fibers.

\subsection{Statistical analysis}

Response variables analyzed were: time of combing, combed fleece weight, down yield and down fiber diameter. Analyses of variance were performed using generalized linear model procedures (SAS, 2008). The statistical model describing a response variable on an animal included comb type (large and small), combing stage (first, second and third stage) and age of the goat (1-4 year old) as fixed effects. Interactions of interest also included in the model were comb type with stage of combing and comb type with age at combing. Least squares means resulting from adjusting the model are presented with their standard error. Differences between means were tested using Duncan's new multiple range test with the level of significance at $P<0.01$. Combing time was plotted to uncorrected measurements of combed fleece weight and down yield for both comb types. Linear regressions were fitted and compared.

\section{Results and discussion}

One goat died after its second combing; otherwise full information on the 40 goats was available. Table 1 presents overall means, standard deviations and ranges for measured variables. Mean combed fleece weight per combing was $26.4 \mathrm{~g}$. Down fiber diameter averaged $19.6 \mu \mathrm{m}$, similar to the $19.5 \mu \mathrm{m}$ observed in the survey of 29 flocks made by Ansari-Renani et al. (2012). The fiber threshold of $30 \mu \mathrm{m}$ used to separate down and hair fibers lays between the maximum average down fiber diameter $(23.1 \mu \mathrm{m})$ and minimum average hair fiber diameter $(38.9 \mu \mathrm{m})$. Table 2 presents least squares means obtained from adjusting the data. The model used explained $32 \%$ of the variability in combed cashmere weight, $19 \%$ of variability in both down yield and time of combing and only $9 \%$ of down fiber diameter.

\subsection{Effects of comb types and combing regimes on cashmere harvest}

Small combs removed about 1.4 times (31.0 vs. $21.7 \mathrm{~g}$ ) more cashmere then large combs (Table 2). The small combs with shorter length and lower diameter of rods penetrate deeper in the fleece and collect more shed fibers than the large combs with longer rods and curved round tips of higher diameter which hardly penetrate the fleece. Although much more cashmere could be combed from 4 year old goats than from 1 year goats, no clear age trend could be detected. The first two combings of a goat did not yield different combed cashmere weight but the third combing yielded considerably less cashmere $(P<0.01)$, in particular if using the small combs $(35.4,37.0$ and $20.6 \mathrm{~g}$, respectively) (Table 2 ). Adding the combed cashmere produced in the three stages with small combs gives about $93 \mathrm{~g}$. This is only $18 \%(93 / 507)$ of the average sheared fleece weight of Raeini goats and only $32 \%(93 /(507 * 0.565))$ of dehaired down which may be obtained from an average

Table 1

Overall arithmetic means, standard deviations (s.d.) and ranges of combed cashmere traits and combing time for experimental Raeini goats.

\begin{tabular}{llcccc}
\hline Variable & $n$ & Mean & s.d. & Minimum & Maximum \\
\hline Combed cashmere weight $(\mathrm{g})$ & 119 & 26.4 & 17.9 & 7.1 & 77.5 \\
Down yield $(\%)$ & 119 & 83.6 & 1.3 & 54.0 & 96.0 \\
Down fiber diameter $(\mu \mathrm{m})$ & 119 & 19.6 & 1.63 & 0.1 & 23.1 \\
Combing time $(\min )$ & 119 & 5.28 & 5.3 & 38.9 & 10.15 \\
Hair fiber diameter $(\mu \mathrm{m})$ & 119 & 50.5 & 66.9 \\
\hline
\end{tabular}


Table 2

Least squares means \pm standard error of combed cashmere traits and combing time.

\begin{tabular}{|c|c|c|c|c|}
\hline Fixed effect & Combed cashmere weight $(\mathrm{g})$ & Down yield (\%) & Down fiber diameter $(\mu \mathrm{m})$ & Combing time ( $\mathrm{min}$ ) \\
\hline Large comb & $21.7 \pm 2.0 \mathrm{~b}$ & $84.3 \pm 0.9$ & $19.7 \pm 0.2$ & $2.79 \pm 0.20 \mathrm{~b}$ \\
\hline Small comb & $31.0 \pm 2.0 \mathrm{a}$ & $83.0 \pm 0.9$ & $19.4 \pm 0.2$ & $3.75 \pm 0.20 \mathrm{a}$ \\
\hline First stage & $28.1 \pm 2.5 \mathrm{a}$ & $84.7 \pm 1.1$ & $19.4 \pm 0.2$ & $3.38 \pm 0.24$ \\
\hline Second stage & $32.0 \pm 2.5 \mathrm{a}$ & $84.3 \pm 1.1$ & $19.6 \pm 0.2$ & $3.57 \pm 0.24$ \\
\hline Third stage & $19.0 \pm 2.5 b$ & $81.9 \pm 1.1$ & $19.8 \pm 0.2$ & $2.87 \pm 0.25$ \\
\hline 1 year old & $20.1 \pm 2.8 c$ & $85.3 \pm 1.2$ & $19.3 \pm 0.2$ & $3.11 \pm 0.28$ \\
\hline 2 year old & $28.5 \pm 2.8 \mathrm{ab}$ & $83.7 \pm 1.2$ & $19.8 \pm 0.2$ & $3.20 \pm 0.28$ \\
\hline 3 year old & $21.6 \pm 2.8 b c$ & $81.0 \pm 1.2$ & $19.3 \pm 0.2$ & $3.26 \pm 0.28$ \\
\hline 4 year old & $35.3 \pm 2.9 \mathrm{a}$ & $84.6 \pm 1.3$ & $19.9 \pm 0.2$ & $3.52 \pm 0.29$ \\
\hline Large - first stage & $20.8 \pm 3.5$ & $82.5 \pm 1.5$ & $19.7 \pm 0.3$ & $2.53 \pm 0.34$ \\
\hline Large - second stage & $27.0 \pm 3.5$ & $86.6 \pm 1.5$ & $19.6 \pm 0.3$ & $3.15 \pm 0.34$ \\
\hline Large - third stage & $17.5 \pm 3.6$ & $83.9 \pm 1.6$ & $19.9 \pm 0.3$ & $2.70 \pm 0.35$ \\
\hline Small - first stage & $35.4 \pm 3.5$ & $86.9 \pm 1.5$ & $19.1 \pm 0.3$ & $4.23 \pm 0.34$ \\
\hline Small - second stage & $37.0 \pm 3.5$ & $82.0 \pm 1.5$ & $19.5 \pm 0.3$ & $3.98 \pm 0.34$ \\
\hline Small - third stage & $20.6 \pm 3.5$ & $79.9 \pm 1.5$ & $19.7 \pm 0.3$ & $3.05 \pm 0.34$ \\
\hline Large - 1 year old & $14.0 \pm 4.0$ & $84.7 \pm 1.8$ & $19.5 \pm 0.3$ & $2.81 \pm 0.40$ \\
\hline Large -2 year old & $20.3 \pm 4.0$ & $84.8 \pm 1.8$ & $19.8 \pm 0.3$ & $2.95 \pm 0.40$ \\
\hline Large -3 year old & $19.4 \pm 4.0$ & $82.9 \pm 1.8$ & $19.4 \pm 0.3$ & $2.91 \pm 0.40$ \\
\hline Large -4 year old & $33.2 \pm 4.1$ & $84.8 \pm 1.8$ & $20.2 \pm 0.4$ & $2.51 \pm 0.41$ \\
\hline Small - 1 year old & $26.3 \pm 4.0$ & $85.8 \pm 1.8$ & $19.1 \pm 0.3$ & $3.41 \pm 0.40$ \\
\hline Small - 2 year old & $36.7 \pm 4.0$ & $82.6 \pm 1.8$ & $19.8 \pm 0.3$ & $3.46 \pm 0.40$ \\
\hline Small - 3 year old & $23.7 \pm 4.0$ & $79.0 \pm 1.8$ & $19.3 \pm 0.3$ & $3.61 \pm 0.40$ \\
\hline Small - 4 year old & $37.4 \pm 4.0$ & $84.4 \pm 1.8$ & $19.6 \pm 0.3$ & $4.53 \pm 0.40$ \\
\hline
\end{tabular}

Least squares means within fixed effect followed by different letters are significantly different $(P<0.05)$.

shorn fleece (Ansari-Renani et al., 2012). Thus, $93 \mathrm{~g}$ of combed cashmere must match the price of $507 \mathrm{~g}$ of shorn cashmere if only the raw cashmere price variable is considered as a decision criterion. If the combed cashmere is transformed by the farmer into added value products the worth of combing may be judged differently since factory dehaired cashmere is expensive and not readily available. Other criteria not analyzed here may also be taken into account. For example: the benefit of leaving guard hairs unshorn to protect goats from climate issues or the availability of labor in the nomad family (De Weijer, 2008). Combing can play an important role in improving the livelihood of nomad cashmere producers. Future research needs to further explore the impact of cashmere combing beyond three sessions in order to develop a more effective harvesting management of shed fibers.

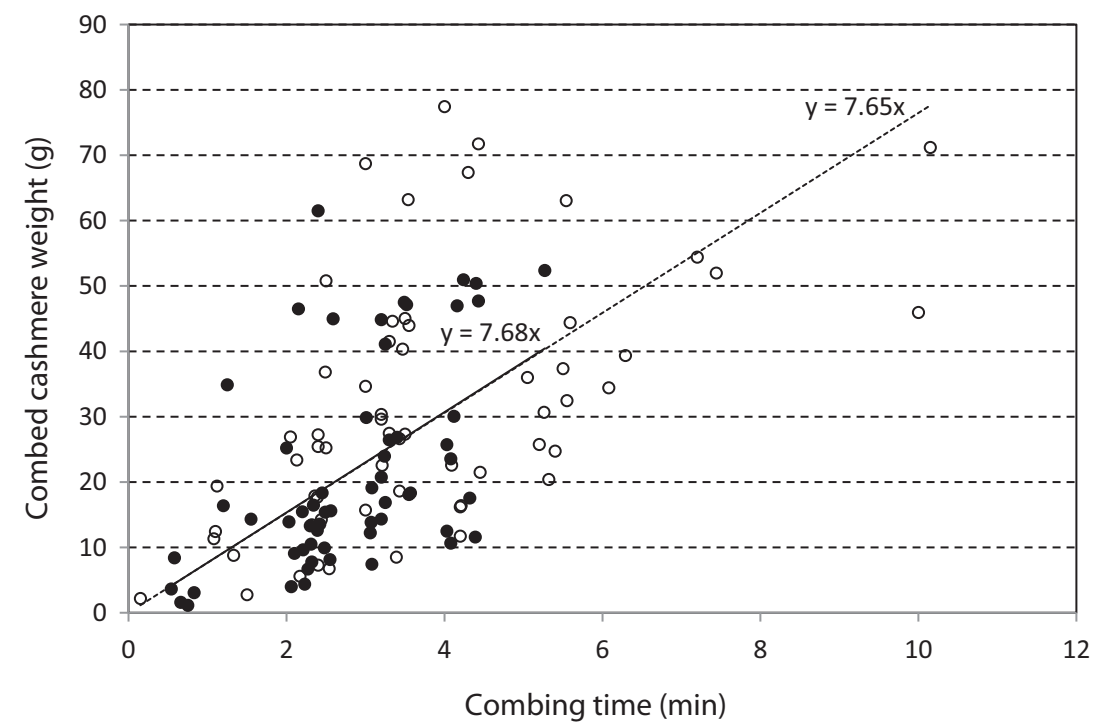

Fig. 3. Relation between combed cashmere weight and combing time using large combs with long rods (solid dots) and small combs with short rods (open dots). Linear regressions forced through the origin for each comb type are almost equal ( $b=7.65$ and $b=7.68 \mathrm{~g} / \mathrm{min}$ ) and significantly different from zero $(P<0.05)$. 


\subsection{Effects of comb types and combing regimes on combing time}

More cashmere is combed if more time is spent in combing. The regression (forced through the origin) indicates an increase of about $7.7 \mathrm{~g} / \mathrm{min}$ (Fig. 3) but the variability between goats is very large. For example goats combed in 4 min yielded from 10 to more than $70 \mathrm{~g}$ of cashmere. Some goats may not even be worth combing. The amount of time spent for combing was much higher with small combs than with large combs. Combing a goat with a small comb took on average $3.75 \mathrm{~min}$ and with a large comb it took $2.79 \mathrm{~min}$ per combing stage. Adding the time spent to comb a goat over the three combing stages yields $11.25 \mathrm{~min}$ with the small comb and $8.37 \mathrm{~min}$ with the large comb. These total times are not very different from the average shearing time of a goat estimated at $10 \mathrm{~min}$ (De Weijer, 2008). It is possible that with increased experience combing time can be decreased and subsequently decrease the cost of family lobor related to collection of cashmere.

\subsection{Effect of comb type and combing regimes on cashmere quality}

Down fiber diameter was not influenced by comb type or combing regime. Down yield decreased in consecutive combings when using small combs but did not do so when using large combs. With large combs first combing results in a low down yield, thus for this trait a significant $(P<0.01)$ type of comb by shearing regime interaction was found.

\section{Conclusion}

Combing can be justified only if a considerable price premium can be obtained from selling combed cashmere instead of selling shorn cashmere, or if the combed cashmere is used to add value on-farm. If this is the case, small combs with short rods are preferable since more cashmere can be collected without affecting its quality.

\section{Acknowledgments}

We are thankful to the Iranian Animal Science Research Institute and the Agriculture and Natural Resources
Center of Kerman province for supporting this project. We also thank the staff of the fiber laboratory of INTA Bariloche, Argentina for the sample analysis. This research was funded by the International Fund for Agricultural Development (IFAD).

\section{References}

Ansari-Renani, H.R., 2001. Seasonal follicle cycle and fibre shedding of Raeini cashmere goats. J. Pajou Sazan., Ministry of Agric. Iran 14 (4), 23-25.

Ansari-Renani, H.R., Ebadi, Z., Moradi, S., Baghershah, H.R., Ansari-Renani, M.Y., Ameli, S.H., 2011a. Determination of hair follicle characteristics, density and activity of Iranian cashmere goat breeds. Small Rumin. Res. 95, 128-132.

Ansari-Renani, H.R., Rischkowsky, B., Mueller, J.P., Moradi, S., 2011b. Cashmere in Iran. Production, marketing and processing. ICARDA - ASRI., pp. 81.

Ansari-Renani, H.R., Mueller, J.P., Rischkowsky, B., Seyed Momen, S.M. Alipour, O., Ehsani, M., Moradi, S., 2012. Cashmere quality of Raeini goats kept by nomads in Iran. Small Rumin. Res. 104, 10-16.

Ansari-Renani, H.R., Rischkowsky, B., Mueller, J.P., Seyed Momen, S.M., Moradi, S., 2013. Nomadic pastoralism in southern Iran. Pastoral. Res. Policy Practice 3 (11), 25.

De Weijer, F., 2008. Cashmere Value Chain Analyses Afghanistan. Accelerating Sustainable Agriculture Program. USAID, pp. 38.

Emami Meibodi, M.A., 1992. Estimation of Genetic Parameters of Raeini Goat Economic Traits. Ferdosi University of Mashad, M.Sc. Thesis.

Gökmen, M., Boztepe, S., 2004. Determination of cashmere fiber production and quality traits in Turkish hair goat. J. Anim. Vet. Adv. 3, $781-784$.

Herrmann, S., Wortmann, F.J., 1997. Opportunities for the simultaneous estimation of essential fleece parameters in raw cashmere fleeces. Livest. Prod. Sci. 48, 1-12.

IWTO, 2000. International Wool Textile Organisation, Test Method Nr. IWTO-58-00

IWTO, 2003. International Wool Textile Organisation, Test Method $\mathrm{Nr}$ IWTO-12-03. In: Measurement of the Mean \& Distribution of Fibre Diameter Using the Sirolan-Laserscan Fibre Diameter Analyser.

McGregor, B.A., 1994. Measuring cashmere content and quality of fleeces using whole fleece and midside samples and the influence of nutrition on test method. Proc. Aust. Soc. Anim. Prod. 20, 186-189.

McGregor, B.A., Kerven, C., Toigonbaev, S., 2011. Sources of variation affecting cashmere grown in the Pamir mountain districts of Tajikistan and implications for industry development. Small Rumin. Res. 99, 7-15.

Petrie, O.J., 1995. Harvesting of Textile Animal Fibres. Food and Agricultural Organization of the United Nations, No. 22, Rome.

SAS, 2008. Version 9.2. SAS Institute Inc., Cary, NC.

Wildman, A.B., 1954. The microscopy of animal textile fibers. Wool Industry $8,289-302$. 